\title{
Impact of Early Childhood Developmental Intervention Programs: Cost-Benefit Analysis Using a Proposed Model
}

\author{
Aravindhan Veerapandiyan ${ }^{1}$, Lama Charafeddine ${ }^{2}$, Durriyah Sinno ${ }^{2}$ and Mohamad A Mikati ${ }^{*}$ \\ ${ }^{1}$ Department of Neurology, University of Rochester Medical Center, Rochester, New York, USA \\ ${ }^{2}$ Department of Pediatrics and Adolescent Medicine, American University of Beirut Medical Center, \\ Beirut, Lebanon \\ ${ }^{3}$ Division of Neurology, Department of Pediatrics, Duke University Medical Center, Durham, North \\ Carolina, USA
}

*Corresponding author: Mohamad A Mikati, Professor, Division of Neurology, Department of Pediatrics, Duke University Medical Center, T0913J Children Health Center, 2301 Erwin Road, Durham, NC 27710, North Carolina, USA, Tel: 919-6684073, Fax: 919-681-8943, E-mail: mohamad.mikati@duke.edu

\begin{abstract}
Objective: Early Childhood Developmental Interventions (ECDIs) were developed with the aim of improving overall functional outcome of children over and above what the home environment provides. Cost-Benefit Analysis (CBA) of ECDIs using a flexible and easy to apply model that can complement the more granular and highly desirable CBA studies that often may be too difficult or too expensive to perform.
\end{abstract}

Methods: Review and analysis of the relevant worldwide literature to determine, on a Percent Per Capita Gross National Product (PCGNP) comparative basis: i) Impact of interventions on cognitive outcomes, ii) Impact of improved cognitive outcome on expected later individualized PCGNP, and iii) Duration of ECDIs and their yearly costs. We subsequently performed a CBA based on an analysis model that uses IQ increases as a proxy for subsequent economic gains resulting from ECDIs.

Results: The model used to calculate the impact of ECDIs during the preschool period (two years: ages 3 through 4), is based on the literature that shows the following: Interventions result in a mean increase of intelligence quotient of approximately 8 points, and a higher intelligence quotient is associated with a higher later PCGNP. Projections of revenue resulting from direct benefits of ECDIs versus initial costs revealed a breakeven point for recuperating costs of ECDI at the age of 24 years (range: $22-33$ years) with a benefit-cost ratio of 4.19 (2.08-6.24).

Conclusion: Our CBA provides a proposed model that can be applied across countries, and that allows for tailored modifications for specific communities (e.g. plugging in different costs for ECDIs). This model could potentially complement the more granular and more desirable cost-benefit studies whenever such studies are not possible to perform but a CBA is nevertheless needed.

\section{Keywords}

Benefit-cost ratio, Preschools, PCGNP, Child development, Intelligent quotient

\section{Introduction}

Optimal stimulation of the developing brain creates the foundation for enhanced lifelong skills in thinking, attitudes, and behavior [1]. Early Childhood Developmental Interventions (ECDI), including parenting programmes, community based interventions and particularly preschool programs, have been developed with the aim of improving overall functional outcome of children over and above what the home environment provides [2-5]. There is increasing evidence from developing and developed countries that those interventions result not only in short term improvements $[3,6]$ but also in long lasting effects on cognitive skills $[7,8]$. Such programs have expenses, and their cost-effectiveness across countries is not yet fully understood.

There are a handful of detailed studies with sufficient data to derive benefit cost estimates of ECDI programs [9-11].

Citation: Veerapandiyan A, Charafeddine L, Sinno D, Mikati MA (2018) Impact of Early Childhood Developmental Intervention Programs: Cost-Benefit Analysis Using a Proposed Model. Int J Pediatr Res 4:029. doi.org/10.23937/2469-5769/1510029

Received: April 06, 2017: Accepted: January 29, 2018: Published: January 31, 2018

Copyright: (C) 2018 Veerapandiyan A, et al. This is an open-access article distributed under the terms of the Creative Commons Attribution License, which permits unrestricted use, distribution, and reproduction in any medium, provided the original author and source are credited. 
However, at this time there are not enough of such longitudinal studies to undertake meta-analyses or otherwise generalize beyond their specific context. In this paper we take a different approach by analyzing the benefit cost estimates of ECDI programs using a model of analysis that can be applied across countries all over the world. We illustrate that a plausible effect size of ECDI programs that is in keeping with the documented global experience of programs can be linked to an extensive evidence base on earnings. Tying these elements with published data on costs of programs allows a calculation of an expected return to ECDI programs. In this paper, we propose an analysis model approach that is intended to complement, but not to replace the cost-benefit studies performed for specific ECDI programs in specific locales.

\section{Materials and Methods}

\section{Cost-benefit analysis}

Overview of the analysis approach: It is a recognized fact that human capita is a major determinant of the wealth or poverty of a nation and that cognitive and non-cognitive skills are determinants of lifelong earnings of individuals $[12,13]$. For example, studies have demonstrated that $I Q$, which is established in early childhood/adolescence, predicts individual income achieved later in adulthood [14]. Thus, our approach to determine the benefit-cost estimates of ECDI programs is based on the effect that these programs can have on IQ as a proxy for a broader range of cognitive as well as non-cognitive gains that result in later increases in Per Capita Gross National Product (PCGNP). To accomplish this, we reviewed the relevant worldwide literature to determine the following: i) Impact of interventions on cognitive outcomes, ii) Impact of improved cognitive outcome on expected later individualized PCGNP, and iii) Duration of ECDIs and their yearly costs. We subsequently performed our cost-benefit analysis by calculating the costs of an ECDI program, and the expected increases in PCGNP, over a lifetime, discounted (3\%) to the base year using data from the above reviews, and formulae based on the above approach and review of literature. The paragraphs below provide the details of our review and methods.

Effects of ECDI programs on IQ: There have been several randomized controlled and longitudinal studies that investigated the effects of ECDIs on cognitive development and IQ [3,15-29], (Table 1). These demonstrate that ECDI programs result in increases in IQ scores not only in children with medical conditions such as preterm and low birth weight infants $[19,21,26,28]$ but also, and perhaps more importantly, in healthy children with normal birth weights as well as disadvantaged children $[3,15-17,20,22-25,27,29,30]$. Despite the variability resulting from the heterogeneity of these programs, their different durations (ranging from 1 year to 6 years), and the range of the length of subsequent follow up (from 1 to 14 years), the majority of these demonstrate convincing effect of ECDIs on IQ. We thus calculated, based on the data available from these studies, that an ECDI program, which lasts an average of about 2 years, results in a mean increase of IQ of approximately 8 points (range 4-12).

Effects of IQ on income: Studies have shown strong statistically significant correlations between national IQs and nation's PCGNP as well as its rate of economic growth [12-14,31,32]. In addition, a recent study in the USA reported that each one point increase in IQ test scores raises income by $\$ 234-\$ 616$ per year [33]. This is equivalent to $0.5 \%-1.3 \%$ of PCGNP per year. This results from a combination of subsequent increased schooling, more learning per year of school as well as from an additional premium on intelligence observed in most wage studies. Thus, based on the above data, we estimated, for the purpose of calculations in our model, that each one point increase in IQ should be associated with an increase in a mean income of about 0.9\% PCGNP per year for each program beneficiary.

Expenditure on ECDI programs: We estimated expenditure on ECDI programs based on two methods:

(i) The first approach was based on what ECDI pro-

Table 1: Studies that demonstrated improvements in IQ with early childhood developmental intervention programs.

\begin{tabular}{|l|l|l|l|}
\hline Studies & Country & Interventions & Improvement in IQ \\
\hline Aboud [15] & Bangladesh & Early childhood preschool program & 0.2 \\
\hline Ade, et al. [16] & India & Preschool education through Anganwadi centers & 10.2 \\
\hline Armecin, et al. [17] & Philippines & Philippine integrated early childhood development program 0.553 SD increase \\
\hline Cicchetti, et al. [19] & USA & Toddler parent psychotherapy & 4.95 \\
\hline Garber [20] & USA & Preschool and family interventions & 10 \\
\hline Grantham-Mc Gregor, et al. [21] & West Indies & Child development intervention program & 8.6 \\
\hline Gutelius, et al. [22] & USA & Cognitive stimulation program & 8.1 \\
\hline Jaramillo, et al. [23] & Cape Verde & Preschool program & 4.41 \\
\hline Jaramillo, et al. [23] & Guinea & Preschool program & 7.27 \\
\hline Love JM, et al. [24] & USA & Early head start program & 0.13 \\
\hline Nordhov, et al. [26] & Norway & Modified mother infant transaction program & 7.2 \\
\hline Olds, et al. [27] & USA & Home visiting by paraprofessionals and nurses program & 3.98 \\
\hline Wasik, et al. [29] & USA & Early Intervention: Project CARE & 0.3 \\
\hline
\end{tabular}

SD: Standard Deviation. 
grams currently actually cost in various countries. Based on the Education for All Global Monitoring report, in 2004, countries in Central and Eastern Europe region spent $22.4 \%$ of their PCGNP per student in such programs for preprimary education, Latin American countries spent about $8 \%$ and countries in the North America and Western European region spent 13.45\% [34].

(ii) The second approach was based on the calculations used by Van Ravens and Aggio (2008) who estimated the costs of early childhood care and education based on the following formula [35]:

Annual RPD (regular program delivery) Cost =

$$
\frac{(\text { PSTAS } * \text { ECCE adjust })}{\text { i.NP }} * \frac{1}{\mathrm{SC} / \mathrm{TC}} * \frac{1}{\mathrm{GS}}
$$

PSTAS: Primary School Teacher's Annual Salary; ECCE: Early Childhood Care and Education; NP: Number of Programs per teacher per year; SC: Salary Cost; TC: Total Cost, and GS: Group Size.

Using the above formula, Van Ravens and Aggio calculated that the program delivery costs per student of early childhood care and education in Arab states were 12.5\%, and in Sub-Saharan Africa $20.8 \%$ of PCGNP. This variability was due to difference in the primary school teacher's annual salary in the above countries which were estimated to be 3 times of PCGNP for the Arab states, and 5 times of PCGNP for Sub-Saharan Africa.

Based on the above two methods, we considered that the yearly cost of a comprehensive high-level ECDI program should be toward average of the above estimates, that is around $14 \%$ of PCGNP, and used that number in our model.

Rationale used in the cost-benefit analysis: In order to derive and use the analysis formulae that are delineated below, we made a number of assumptions that were based on a detailed and balanced review of the literature. These included: 1) Increases in IQ occurring secondary to ECDIs will have an impact on income that is similar to naturally occurring differences in IQ and are a proxy for the range of gains from ECDIs. This assumption is supported by several studies reporting that ECDIs increase performance in cognitive domains and result in financial gains to society from increases in income of individuals, as well as from increases in tax payments due to increased income [7,8,30,36-40]. The literature also indicates a strong association between cognitive and psychosocial skills at young ages, and long term education attainment, earnings, and employment outcomes $[41,42]$. 2) ECDI programs which will be implemented in the future will have costs and beneficial effects on IQ that are similar to the interventions reviewed above $[16,20,23,25,29]$. Whereas we can never be sure of what will happen in the future, it is reasonable to assume that programs that will be implemented in the future will have effectiveness which is at least in the same range as those of the past. Also, we assumed that the impact of increases in IQ on PCGNP percentage is similar, on average, across countries [33]. Although, this impact is bound to vary from one country to another, we did base our calculations and estimates on specific data derived from all over the world, from developed and developing countries. Our model actually also has the flexibility and allows the use of individual country data, for example, of the specific initial costs of ECDIs in that country, whenever such data are available. We also performed low, intermediate, and high impact analyses to account for potential variability. 3) We assumed start of intervention at age 3 years for duration of 2 years, with gainful employment starting at age 18 years and retirement at age 65 years. This is likely to be a somewhat conservative estimate for developing countries and the opposite for developed countries: The age at start of gainful employment in developing countries is often earlier than that of developed ones. We assumed an annual discount rate of 3\% in keeping with a number of key studies in the literature [43-48], and then we illustrated that our results are not dependent on this assumed discount rate by estimating the rate of return for ECDIs (see below).

Formulae to calculate cumulative costs and revenue: The formulae we used for cost-benefit analysis were:

Total Cost of intervention $=\sum\left[\mathrm{C} * 1 /(1+\mathrm{r})^{\mathrm{n}}\right]$

$\mathrm{C}=$ Cost of intervention expressed in $\$$ or in $\%$ of PCGNP (14\% of PCGNP); $r=$ discount rate which is 0.03 $(3 \%) ; n=$ current age-3.

Based on the rationale explained in the above sections, the estimate of the \% of PCGNP spent on ECDIs when the intervention started at the age of 3 years that we used was $14 \%$, and during the next year (age 4) was another $14 \%$ with a $3 \%$ discount rate.

Total Revenue or Benefits from intervention = $\sum\left[\mathrm{R} * 1 /(1+\mathrm{r})^{\mathrm{n}}\right]$

$\mathrm{R}=$ revenue/year expressed in $\$$ or in \% PCGNP; $r=$ discount rate which is $0.03(3 \%)$;

$\mathrm{n}=$ age (starting with 18 years, the expected age of start if employment) -3 .

Based on the rationale explained in the above sections, the estimate of the mean \% increase in income for each point increase in IQ per year that we used was $0.9 \%$ PCGNP, the yearly per capita cost for an ECDI program was $14 \%$ of PCGNP, and the duration of ECDI which we used was two years (age 3 and 4). The expected gains in lifetime earnings attributed to ECDI programs were calculated from age 18 years until 65 years as a \% of the PCGNP to which the $3 \%$ yearly discount was applied. In addition, we performed the calculations at three levels of potential effect of ECDIs on IQ: Low, intermediate and high estimates. 


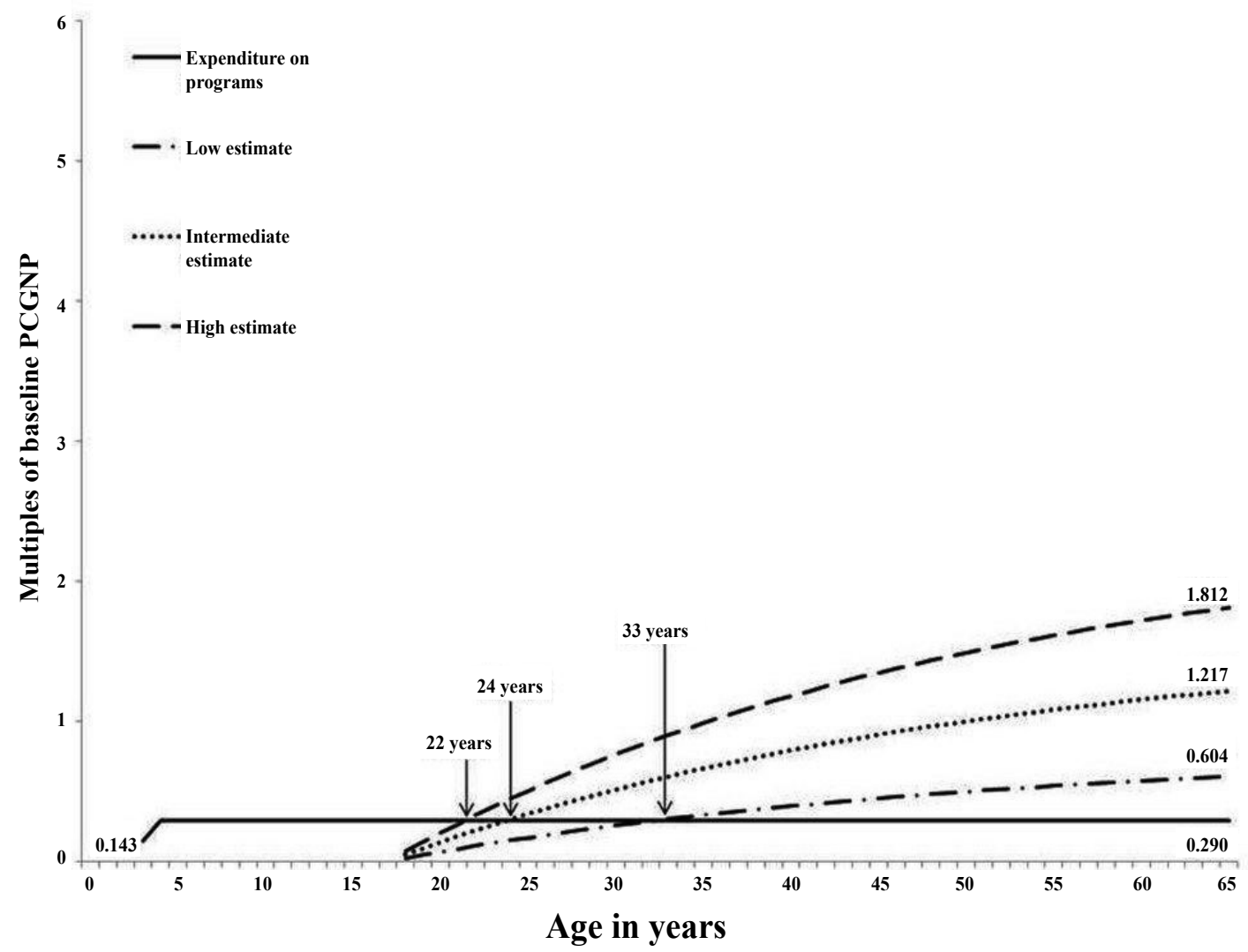

Figure 1: Cost-benefit analysis-projection: Low estimate: Income based on the lowest effect of interventions on IQ. Income starts exceeding the cost at 33 years of age; Intermediate estimate: Income based on average effects of interventions on IQ. Income starts exceeding the cost at the age of 24 years; High estimate: Income based on largest effect of interventions on IQ. Income starts exceeding the cost at the age of 22 years.

In our intermediate calculation we used the mean effect of intervention on IQ of 8 points. We then repeated the calculations using the lower value of the range (4.0 points) and the higher value of the range (12.0), as per the review of the literature presented in the above section.

Internal return rate: We also estimated the annual Internal Return Rate (IRR) of ECDIs which is the discount rate that would lead to a benefit-cost ratio of 1 , based on our analysis model.

\section{Results}

\section{Expenditures on ECDI programs}

The Present Discounted Value (PDV) cost spent per person by the country on ECD programs projected over 65 years of age as per our calculations was 0.2902 PCGNP (Figure 1).

\section{Direct economic benefits of ECDIs on PCGNP}

Intermediate estimate: Our calculations showed that the PDV (3\%) projected income at the age of 65 years of a person who had the moderate effect of intervention on IQ would be 1.216 PCGNP. Low estimate: The PDV projected income at the age of 65 years of a person who had a lower effect of intervention on IQ would be 0.604 PCGNP. High estimate: The PDV projected income at the age of 65 years of a person who had a higher effect of intervention on IQ would be 1.812 PCGNP.

\section{Net economic gain}

Intermediate estimate: Our calculations showed that the expected economic gain over a lifetime at the age of 65 years per person i.e., difference between the effect of intervention and the expenditure on intervention expressed as PDV is 0.925 PCGNP. The age at which the total PDV income gains starts exceeding the cost (breakeven point) is 24 years (Figure 1). The benefit cost ratio with $3 \%$ discount rate projected to the age of 65 years is 4.19. Low estimate: The expected economic gain over lifetime is 0.314 PCGNP per person. The breakeven age is 33 years (Figure 1) and the benefit cost ratio is 2.08 . High estimate: The expected economic gain over lifetime is 1.522 PCGNP per person. The breakeven age is 22 years (Figure 1), and the benefit cost ratio is 6.24.

We also used our model to estimate the total benefits including indirect benefits that can occur after completion of ECDI. Such indirect benefits can result from decreased repetition of grades, decreased need for special education, decreased truancy and delinquency, and other benefits as detailed in the discussion. To do that we performed the same type of calculations described above but started the benefit calculations as of age 4 since the above indirect benefits start in childhood and the direct benefits start after employment starts. We found that this estimate of the total benefits resulted at age 65 years in a benefit-cost ratio of 7.02 (2.038 of PC- 
Table 2: Studies that demonstrated the effects of IQ on Income.

Lynn, et al. [12]; Rushton [13]; Lynn, et al. [14];

$>$ Correlation of measured IQs of 113 nations and their per capita income was 0.68 .

$>$ Correlation between IQ of all the 192 nations IN the world and their per capita income was 0.60.

> Nations whose populations have high IQs have high per capita incomes and these enable them to provide high-quality nutrition, education and health care for their children and these in turn enhance their children's intelligence.

Templer, et al. [31]

> Mean IQ of 129 countries correlated with per capita income, skin color, and winter and summer temperatures, conceptualizing skin color as a multigenerational reflection of climate.

$>$ The highest correlations were -0.92 (rho $=0.91$ ) for skin color, -0.76 (rho $=0.76$ ) for mean high winter temperature, -0.66 $($ rho $=0.68)$ for mean low winter temperature, and -0.63 (rho $=0.74)$ for real gross domestic product per capita.

Zagorsky [33]

$>$ Tracked a large group of young United States baby boomers using national longitudinal survey (NLSY79). IQ correlated with annual income (0.3) and with net worth (0.16).

$>$ Each point increase in IQ test scores raises income by between $\$ 234$ and $\$ 616 /$ year or $0.9-2.5 \%$ of PCGNP (mean $1.7 \%$ ).

Table 3: Studies that performed cost-benefit analysis of specific early childhood developmental intervention programs in specific locales and their estimated benefit-cost ratio in comparison to our analysis model.

\begin{tabular}{|l|l|l|}
\hline Studies & $\begin{array}{l}\text { Age at which cost-benefit analysis was } \\
\text { performed (years) }\end{array}$ & Benefit-Cost ratio \\
\hline Perry preschool program [39] & 27 & $7.16^{*}$ \\
\hline Chicago child parent center [11] & 26 & $10.83^{*}$ \\
\hline Abecedarian preschool project [39] & 22 & $2.69^{*}$ \\
\hline Bolivian preschool program PIDI [30] & 60 & 2.93 \\
\hline Preschool program in Turkey [49] & 65 & 2.18 \\
\hline Incredible years parenting program [2,10] & 30 & 13.3 \\
\hline Our analysis & $\mathbf{6 5}$ & $\mathbf{4 . 1 6}$ \\
\hline
\end{tabular}

${ }^{*}$ Cost benefit analyses done at the specified ages and projected over life time to obtain the benefit-cost ratio. Chicago Child Parent Center - projected through 65 years of age).

GNP/0.29 of PCGNP) and in a break-even age of 8-years.

\section{Internal return rate}

Our calculations showed that the IRR of ECDIs based on direct benefits is $8 \%$, and on total benefits is $23 \%$.

\section{Discussion}

In this study, we determined the benefit cost estimates of ECDIs by developing a model that can be applied worldwide by using IQ as a proxy for a range of gains secondary to ECDIs: Numerous studies involving different nations in the world have demonstrated positive correlation between IQ and economic gains and that nation whose population have high IQs have high per capita incomes and these enable them to provide high-quality nutrition, education and health care for their children and these in turn enhance their children's intelligence (Table 2). This is a simplified approach that can be used across countries as compared to the more detailed and granular analyses that have been done in specific programs in specific societies. These previous studies have used either direct benefits $[9,30,49]$ or total benefits [39] to estimate the benefit-cost ratio of their specific ECDIs (Table 3). The numbers that our analysis model provides are commensurate to those from these prior studies as summarized in the paragraph below.

Gowani, et al. calculated the cost effectiveness of a community based intervention by taking the costs per community health worker annualized for each of the intervention cells divided by effectiveness figures.
The cost of the intervention was approximately $\$ 4$ per month per child.

Behrman, et al. estimated a benefit-cost ratio of 2.93 at the age of 60 years from the bolivian preschool program PIDI focusing exclusively on direct benefits of earnings [30]. Our model predicts that at the above age the ratio of direct benefits to cost is 3.97 (1.154 PCGNP/0.29 PCGNP). Similarly, the cost benefit analysis of preschool programs in Turkey based on direct benefits derived from the expected increase in lifetime productivity revealed a benefit-cost ratio of 2.18 [49]; Our model predicts a ratio of 4.19 (1.22 PCGNP/0.29 PCGNP). In addition, benefit-cost ratio from the Perry Preschool program using total benefits (that include in addition to the direct benefits of increased monthly earnings, the indirect benefits of increased school attendance, decreased expenditures on education, increased completion of high school, decreased need for special education services, victim savings etc.) measured at the age of 27 years and projected over life-time was 7.16 [39]. The ratio of total benefits to cost from Chicago Child-Parent Centers pre-school program measured at the age of 26 years and projected over life time through age 65 years was 10.83 [11]. Finally, the ratio from North Carolina Abecedarian project with cost and benefits measured at the age of 22 years and projected over life time was 2.69 [39]. Our analysis predicted a close total benefits to cost ratio projected over a life time (65 years of age) of 7.02 (2.034 PCGNP/0.29 PCGNP). Thus, while the cost-benefit estimates show some variations due to the methods 
used and to expected program and country differences, it is important to note that our model's benefit to cost ratio predictions are close to those found in the above granular studies. In fact, our model's estimates lie in the middle; For some of the studies it results in higher and for others in lower ratios. This supports the validity of our approach and its applicability to a range of programs in different countries across the world. Our model also has the flexibility of being able allow specific modifications for specific countries (e.g. plugging in different costs for ECDIs or of discount rate relevant to the country in question) whenever needed.

The benefit stream reported here is a conservative estimate in many respects. Most notably, we focus mostly on the direct benefits from an increased stream of earnings (Figure 1). As is well documented, ECDI programs can have several additional indirect benefits such as reduced costs of remedial and other forms of special education, reduced crime, reduced grade repetition/ grade retention, reduction in welfare payments, reduction in the enrolling children into special schools, reduced divorce rates, educational attainments, and higher rates of holding credit cards [7,8,30,36-40]. These benefits are less universally studied and, moreover, require a different set of calculations from those used in this paper to better estimate them. As these indirect benefits are almost certainly both positive and substantial, the direct benefit to cost ratio we report is likely to be an underestimate. Nevertheless, we did use our approach to estimate the total (and not only the direct) benefit-cost ratio, as presented in the results section, in order to demonstrate the flexibility of our analysis model and to compare its predictions to previous studies that have calculated the total (rather than only direct) benefit to cost ratios. Another point is that the formula we used assumes that there are no productivity gains in the economy other than those achieved via ECDIs. If, as is more plausible, PCGNP grows over the period studied at a rate, $g$, due to other capital investments and wage earnings grow proportionally then in addition to a discounting factor of $r$ for the benefits, one should include the rate of growth of PCGNP.

Thus, the benefit stream would be

$$
\mathrm{R}_{\mathrm{g}}=\sum\left[\mathrm{R} *\{(1+\mathrm{g}) /(1+\mathrm{r})\}^{\mathrm{n}}\right]
$$

The term within the curly brackets \{\} can, in fact, be greater than 1, implying that the benefits in each year in the future increase over time when productivity is growing rapidly.

In any cost-benefit analysis, there are bound to be potential variations, or even deviations, higher or lower, from the numbers used in that analysis. One potential, arguably worst case scenario would be a null effect of $E C D I s$ on IQ, i.e., ECDIs do not result in any increases in $I Q$, in which case, there may not be any related finan- cial benefits. For example, children participated in Perry preschool program outscored the comparison group in $\mathrm{IQ}$ and many other intellectual and language tests from after the first preschool year up to age of 7 years, but afterwards the gains faded-out $[38,40]$. However, as reviewed above, the literature predominantly indicates that the short-term gains in IQ even if not accompanied by long-term ones, are a proxy for a range of economically beneficial gains to society which eventually have been shown to materialize in the labor force [15-17,19$30,50]$. As mentioned, the non-cognitive gains are a parallel contributor to gains from ECDIs [51]. Another potential deviation is that the estimated expenditure on ECDIs that we used in our calculations (14\% PCGNP) is too low to result in the desired effects. However, this level of expenditure is the average of what such programs cost and even much lower levels of expenditure have resulted in major impacts on IQ and in major economic benefits $[16,23,25,52]$. For example, a preschool program in Kenya that resulted in an increase in IQ of 0.4 SD/year had an expenditure of approximately $3 \%$ of its PCGNP $[25,52,53]$. Similarly, another study from Guinea showed that lower costs did not reduce the impact on IQ [23]. Thus the average used here is not particularly parsimonious. An additional limitation in the proposed model would be estimating life-term earnings based on schooling. The equating of life-time earning to the increment in wages from schooling is fairly standard. For individuals who are voluntary outside the labor force, it is common to assume that the increment to productivity is the same or greater than wages $[47,54]$.

In conclusion, our cost-benefit analysis of ECDIs based on the approach of using IQ as a proxy for a range of gains secondary to interventions showed that the ECDI programs are cost-effective. This is based on our calculations that show that the calculated direct benefits alone exceed the costs under any circumstances of an average discounted rate of less than $8 \%$, a rate which is very unlikely to be sustained over 63 years in any country. This supports the rationale for investment in preschool education by Governmental and Non-Governmental Organizations across the world. In addition, our analysis proposes a novel model to calculate benefit-cost estimates of ECDIs that can be applied using general "average" assumptions or using specific data from specific countries across the world. Further validation of the proposed model will need to be conducted on specific programs in specific countries. Accomplishing this may help establish this analysis model as a potentially useful tool when more granular specific studies are impossible to perform.

\section{Acknowledgment}

We would like to acknowledge Dr. Harold Alderman for providing advice and encouragement for publishing this article.

\section{Conflicts of Interest and Source of Funding}

None declared. 


\section{References}

1. Holt RL, Mikati MA (2011) Care for child development: Basic science rationale and effects of interventions. Pediatr Neurol 44: 239-253.

2. Batura N, Hill Z, Haghparast-Bidgoli H, Lingam R, Colbourn $T$, et al. (2015) Highlighting the evidence gap: How cost-effective are interventions to improve early childhood nutrition and development? Health Policy Plan 30: 813-821.

3. Aisha K Yousafzai, Muneera A Rasheed, Arj umand Rizvi, Robert Armstrong, Zulfiqar A Bhutta, et al. (2014) Effect of integrated responsive stimulation and nutrition interventions in the Lady Health Worker programme in Pakistan on child development, growth, and health outcomes: A cluster-randomised factorial effectiveness trial. Lancet 384: 1282-1293.

4. Bogard K, Takanishi R (2005) PK-3: An aligned and coordinated approach to education for children 3 to 8 years old. Social Policy Report. SRCD 19.

5. Arthur J Reynolds (2003) The added value of continuing early intervention in to the primary grades. In: Wang MC, Walberg HJ, Early Childhood Programs for a New Century. Child Welfare League Am, Press, Washington, 163-196.

6. Schweinhart LJ, Weikart DP (1998) High/Scope perry preschool program effects at age twenty-seven. In: Crane J, Social Programs that work. Russell Sage Foundation, New York, 148-162.

7. Frances A Campbell, Craig T Ramey (1995) Cognitive and school outcomes for high risk African-American students at middle adolescence: Positive effects of early intervention. American Educational Research Journal 32: 743-772.

8. Frances A Campbell, Craig T Ramey, Elizabeth Pungello, Joseph Sparling, Shari Miller-Johnson, et al. (2002) Early childhood education: Young adult outcomes from the Abecedarian project. Applied Developmental Science 6: 42-57.

9. Gowani S, Yousafzai AK, Armstrong R, Bhutta ZA (2014) Cost effectiveness of responsive stimulation and nutrition interventions on early child development outcomes in Pakistan. Ann N Y Acad Sci 1308: 149-161.

10. O'Neill D (2009) A Cost-Benefit analysis of early childhood intervention: Evidence from a randomised evaluation of a parenting programme.

11. Reynolds AJ, Temple JA, White BA, Ou SR, Robertson DL, et al. (2011) Age 26 cost-benefit analysis of the child-parent center early education program. Child Dev 82: 379-404.

12. Lynn R, Vanhanen $T$ (2006) IQ and Global Inequality. GA: Washington Summit Publishers, Atlanta.

13. Rushton PJ, Lynn Richard, Vanhanen Tatu (2006) Review of $I Q$ and Global Inequality. Personality and Individual Differences 41: 983-985.

14. Lynn R, Vanhanen T (2002) Intelligence and the Wealth and Poverty of Nations. GA: Washington Summit Publishers.

15. Aboud FE (2006) Evaluation of an early childhood preschool program in rural Bangladesh. Early Childhood Research Quarterly 21: 46-60.

16. Ade A, Gupta SS, Maliye C, Deshmukh PR, Garg BS, et al. (2010) Effect of improvement of pre-school education through Anganwadi center on intelligence and development quotient of children. Indian J Pediatr 77: 541-546.

17. Armecin Graeme, Behrman Jere R, Duazo Paulita, Ghuman Sharon, Gultiano Socorro, et al. (2006) Early Childhood Development through an Integrated Program: Evidence from the Philippines. The World Bank.
18. Camilli G, Vargas S, Ryan S (2010) Meta-Analysis of the effects of early education interventions on cognitive and social development. Teachers College Record 112: 579-620.

19. Cicchetti D, Rogosch FA, Toth SL (2000) The efficacy of toddler-parent psychotherapy for fostering cognitive development in offspring of depressed mothers. J Abnorm Child Psychol 28: 135-148.

20. Garber, Howard L (1988) The Milwaukee project: Preventing mental retardation in children at risk. American Association on Mental Retardation, Washington.

21. Grantham-Mc Gregor S, Powell C, Walker S, Chang S, Fletcher P, et al. (1994) The long-term follow-up of severely malnourished children who participated in an intervention program. Child Dev 65: 428-439.

22. Margaret F Gutelius, Arthur D Kirsch, Sally Macdonald, Marion R Brooks, Toby McErlean, et al. (1972) Promising results from a cognitive stimulation program in infancy. $A$ preliminary report. Clincal Pediatrics 11: 585-593.

23. Jaramillo A, Tietjen K (2001) Early childhood development in Africa - Can we do more for less? A look at the impact and implications of preschools in Cape Verde and Guinea. World Bank 48.

24. Love JM, Kisker EE, Ross C, Raikes H, Constantine J, et al. (2005) The effectiveness of early head start for 3-yearold children and their parents: Lessons for policy and programs. Dev Psychol 41: 885-901.

25. Malmberg LE, Mwaura P, Sylva K (2011) Effects of a preschool intervention on cognitive development among East-Africsn preschool children: A flexibly time-coded growth model. Early Childhood Research Quaterly 26: 124133.

26. Nordhov SM, Ronning JA, Dahl LB, Ulvund SE, Tunby J, et al. (2010) Early intervention improves cognitive outcomes for preterm infants: Randomized controlled trial. Pediatrics 126: e1088-e1094.

27. Olds DL, Robinson J, O'Brien R, Luckey DW, Pettitt LM, et al. (2002) Home visiting by paraprofessionals and by nurses: A randomized, controlled trial. Pediatrics 110: 486-496.

28. Alicia Spittle, Jane Orton, Peter Anderson, Roslyn Boyd, Lex W Doyle, et al. (2012) Early developmental intervention programs post hospital discharge to prevent motor and cognitive impairments in preterm infants. The Cochrane Library: The Cochrane Collaboration.

29. Wasik BH, Ramey CT, Bryant DM, Sparling JJ (1990) A longitudinal study of two early intervention strategies: Project CARE. Child Dev 61: 1682-1696.

30. Behrman JR, Cheng Y, Todd PE (2004) Evaluating preschool programs when length of exposure to the program varies: A nonparametric approach. Review of Economics and Statistics 86: 108-132.

31. Templer DI, Arikawa H (2006) Temperature, skin color, per capita income, and IQ: An international perspective. Intelligence 34: 121-139.

32. Alderman H, Behrman J (2006) Reducing the incidence of low birth weight in low-income countries has substantial economic benefits. World Bank Research Observer 21: 25-48.

33. Zagorsky JL (2007) Do you have to be smart to be rich? The impact of IQ on wealth, income and financial distress. Intelligence 35: 489-501.

34. Education for All Global Monitoring Report (2007) Strong foundations: Early childhood care and education, UNESCO. 
35. Jan Van Ravens, Aggio C (2008) Expanding early childhood care and education: How much does it cost? A proposal for a methodology to estimate the costs of early childhood care and education at macro-level, applied to the Arab States. $\left(46^{\text {th }}\right)$, Bernard van Leer Foundation, Working paper in Early Childhood Development.

36. Gross RT, Spiker D, Ramey CT (1990) Enhancing the outcomes of low-birth-weight, premature infants. A multisite, randomized trial. The Infant Health and Development Program. JAMA 263: 3035-3042.

37. Arthur J Reynolds, Judy Temple, Barry A White, Suh-Ruu Ou, Dylan L Robertson, et al. (2002) Age 21 cost-benefit analysis of the title i chicago child-parent centers. Educational Evaluation and Policy Analysis 24.

38. Schweinhart LJ, Montie J, Xiang Z (2005) Lifetime effects: The High/Scope perry preschool study through age 40. Ypsilanti, MI: High/Scope Press.

39. Reynolds AJ, Temple JA (2008) Cost-effective early childhood development programs from preschool to third grade. Annu Rev Clin Psychol 4: 109-139.

40. Schweinhart LJ, Barnes HV, Weikart DP, W Steven Barnett, Ann S Epstein, et al. (1993) Significant benefits: The High-Scope Perry Preschool study through age 27. Ypsilanti, MI: High/Scope Press.

41. Currie J, Duncan Thomas (2001) Early test scores, socioeconomic status, school quality and future outcomes. Research in Labor Economics 20: 103-132.

42. Neal D, Johnson W (1996) The role of pre-market factors in black-white wage differences. Journal of Political Economy 104: 869-895.

43. Horton S, Alderman H, Rivera JA (2008) Copenhagen consensus 2008, hunger and malnutrition: Challenge paper. Copenhagen Consensus Center.

44. Dean T Jamison, Joel G Breman, Anthony R Measham, George Alleyne, Mariam Claeson, et al. (2006) Disease control priorities in developing Countries. ( $2^{\text {nd }}$ edn), The World Bank, Oxford University Press, Washington, New York.

45. Dean T Jamison, Joel G Breman, Anthony R Measham, George Alleyne, Mariam Claeson (1993) Disease control priorities in developing Countries. ( $2^{\text {nd }}$ edn), Oxford University Press, New York.

46. Mathers CD, Ezzati M, Lopez AD (2007) Measuring the burden of neglected tropical diseases: The global burden of disease framework. PLoS Negl Trop Dis 1: e114.

47. Orazem PF, Glewwe P, Patrinos H (2008) Copenhagen Consensus 2008 Challenge Paper: Education.

48. Global Burden of Disease: Disability weights, discounting and age weighting of DALYs. World Health Organization.

49. Kaytaz MA (2004) A cost benefit analysis of preschool education in Turkey. Mother Child Education Foundation.

50. Hoddinott J, Maluccio JA, Behrman JR, Flores R, Martorell $R$, et al. (2008) Effect of a nutrition intervention during early childhood on economic productivity in Guatemalan adults. Lancet 371: 411-416.

51. Heckmann J, Stixrud J, Urzua S (2006) The effects of cognitive and non-cognitive abilities on labor market outcomes and social behavior. Journal of Labor Economics 24: 411482.

52. Mwaura PAM, Mohamed BT (2008) Early Childhood Development Program: Making a difference. In: Garcia M, Pence AR, Evans J, Africa's Future, Africa's Challenge Early Childhood Care and Development in Sub-Saharan Africa. The World Bank, Washington, 389-406.

53. Shireen Issa (2006) A costing model of the Madrasa Early Childhood Development Program in East Africa. Association for the Development of Education in Africa. Doc C-4.3,1-29.

54. Lomborg B (2009) Global Crises, Global Solutions: Costs and Benefits. Cambridge: Cambridge University Press. 